1972). 'Experiments I and II also indicate that light adaptation can, under certain circumstances, increase target detection. This finding is consistent with the argument that light adaptation can reduce the influence of luminance summation on masking (see Eriksen, 1966). It is also consistent with the idea that light adaptation reduced the mask's efficiency by reducing the magnitude of the neurological "on-response" it produces (see Boynton \& Kandel, 1957). Both of these hypotheses of backward masking assume that the target and the mask sum together or are integrated in the visual system. As such, neither of them predicts U-shaped or masking functions. The possibility is suggested that temporal integration mechanisms may determine absolute levels of masking, but not necessarily the shape of the masking function.

\section{REFERENCES}

Boynton, R. M., \& Kandel, G. On responses in the human visual system as a function of adaptation level. Journal of the Optical Society of America, 1957, 47, 275-285.

Bridgeman, B. Metacontrast and lateral inhibition. Psychological Review, 1971, 78, 528-539.
Cox, S., \& Dember, W. N. U-shaped metacontrast functions with a detection task. Journal of Experimental Psychology, 1972, 95, 327-333.

Dixon, W. J. BMD $\emptyset 5 \mathrm{R}$ polynomial regression. In W. J. Dixon (Ed.), $B M D$ biomedical computer programs. Los Angeles: University of California Press, 1967.

Eriksen, C. W. Temporal luminance summation effects in backward and forward masking. Perception \& Psychophysics, 1966, 1, 87-92.

Eriksen, C. W., Becker, B. A., \& Hoffman, J. E. Safari to masking land: A hunt for the elusive U. Perception \& Psychophysics, $1970,8,245-250$.

Kahneman, D. Method, findings and theory in studies of visual masking. Psychological Bulletin, 1968, 69, 404-425.

Purcell D. G. Stewart, A. L. \& Dember, W. N. Backward masking: Facilitation through increased target-field luminance masking: Facilitation through increased target-field lum

Shurman, D. L. Predictive validity of a Rashevsky-Landah neural net: Test of a model of masking for form. Perception \& Psychophysics, 1972, 12, 183-186.

Weisstein, N. A Rashevsky-Landahl neural net: Simulation of metacontrast. Psychological Review, 1968, 75, 494-521.

(Received for publication November 12, 1973.)

\title{
Detection of single letters and letters in words with changing vs unchanging mask characters*
}

\author{
W. K. ESTES, ELIZABETH L. BJORK†, and EDITH SKAAR \\ Rockefeller University, New York, New York 10021
}

\begin{abstract}
With a forced-choice procedure and tachistoscopic displays, accuracy of identification was compared for letters presented alone vs the same letters embedded in words or in nonword letter strings. The advantage for single letters over letters embedded in words or nonwords was found to depend jointly upon characteristics of the pre- and postmasks and change vs no change in mask characters in nontarget locations at the onset of single letter displays.
\end{abstract}

In contrast to the finding of Reicher (1969) and Wheeler (1970) that letters are better identified when embedded in words than when presented alone, several more recent studies (Bjork \& Estes, 1973; Massaro, 1973; Thompson \& Massaro, 1973) have reported a single letter advantage. All of these studies utilized tachistoscopic presentations with similar exposure

*The research reported was supported in part by USPHS Grant GM16735 from the National Institute of General Medical Sciences.

+Now at the University of Michigan. durations, but there has been one principal difference in procedure. In the studies showing a word advantage, the target letters for a trial have been indicated to the $\mathrm{S}$ by means of a postexposure cue, whereas in the studies showing a single-letter advantage, the target letters have been known in advance and held constant over a block of trials. It has been suggested (Bjork \& Estes, 1973; Massaro, 1973) that the latter procedure provides stricter control of effects of redundant information from word contexts at the decision level.

However, there are also differences between the two basic procedures which might operate at the perceptual 
Table 1

Design of Single Display Trials and Percentages of Correct Detections for All Conditions

\begin{tabular}{|c|c|c|c|c|}
\hline \multirow[b]{2}{*}{ Group } & \multirow{2}{*}{$\begin{array}{l}\text { SL Trial } \\
\text { Sequence }\end{array}$} & \multicolumn{3}{|c|}{ Display Type } \\
\hline & & Single & Word & Nonword \\
\hline 1 & $\begin{array}{l}\$ \$ \$ \$ \\
\$ \$ L \$ \\
\$ \$ \$ \$\end{array}$ & 67 & 52 & 57 \\
\hline 2 & $\begin{array}{l}\text { \#\#\#\# } \\
\text { \$\$L\$ } \\
\# \# \#\end{array}$ & 90 & 83 & 82 \\
\hline 3 & $\begin{array}{l}\text { \#\#\#\# } \\
\text { \#\#L\# } \\
\text { \#\#\#\# }\end{array}$ & 95 & 83 & 82 \\
\hline 4 & $\begin{array}{l}\$ \$ \$ \$ \\
\# \# L \# \\
\$ \$ \$ \$\end{array}$ & 57 & 55 & 57 \\
\hline
\end{tabular}

Note-Groups 3 and 4 from $B$ \& $E, 1973$.

level. For example, in the studies of Massaro (1973) and Thompson and Massaro (1973) the target letter was presented alone on single-letter (SL) trials and hence might have an advantage in terms of figure-ground contrast over letters embedded in words $(W)$ or nonword (NW) letter strings. In the study of Bjork and Estes (1973), this problem was bypassed in that the target letter on SL trials was embedded in a row of noise characters, either \$ signs or \# signs, which served also as pre- and postmasks. Their result was a substantial SL advantage with the less effective \# masks and no difference between SL and $\mathrm{W}$ trials with the more effective $\$$ masks. The suggested interpretation was that the more effective characters in the pre- and postmask degrade the inputs from all display positions sufficiently that lateral masking occurs primarily below the level of features and therefore yields no difference between SL and $\mathrm{W}$ contexts.

But there is still a subtle confounding involving the SL vs $\mathrm{W}$ comparison in the Bjork and Estes study. Namely, with \# pre- and postmasks, there was no change of characters at positions other than that of the target character from premask to display to postmask on SL trials, since the \# signs also occurred at the nontarget positions in all SL conditions. With $\$$ pre- and postmasks, however, there was a change at nontarget positions from $\$$ to \# to $\$$.

It appeared on the basis of other evidence in the study that this difference between change and no change at nontarget positions could not account wholly for the SL advantage, but the point deserves explicit investigation. The main experiment of the present study completes the design of this aspect of the Bjork and Estes (1973) study to produce a factorial comparison of effective and ineffective pre- and postmask characters with change vs no change at nontarget positions on SL trials.

A subsidiary experiment in the present study checks on the effect of another procedural difference between the two groups of preceding experiments by including a post-exposure cue for position of the target letter, a feature included in the studies of Reicher (1969) and Wheeler (1970), but not in those of Bjork and Estes (1973), Massaro (1973), or Thompson and Massaro (1973).

\section{METHOD}

\section{Subjects and Apparatus}

The Ss were 12 young adults with no previous experience in tachistoscopic studies who were paid for their services. The apparatus was the same as that of Bjork and Estes (1973). Characters were presented on the screen of an oscilloscope, letters subtending approximately $.75 \mathrm{deg}$ visual angle in width and interletter spaces approximately $.5 \mathrm{deg}$. The $\mathrm{S}$ indicated his response on each trial by pressing one of two response keys which were centered on a tabletop in front of the display screen.

\section{Procedure}

The Ss were informed about the general nature of the experiment but not about the particular types of displays included. They received no information concerning correctness of their responses.

A trial began with a 2-sec exposure of a row of mask characters followed by the SL, W, or NW display for $25 \mathrm{msec}$, and then a row of mask characters which remained in view until the $S$ operated a response key and terminated the trial. The preand postmask characters occupied the same positions on the screen that were occupied by the letters of the display during the exposure itself. The displays always occupied four positions in a horizontal row centered on the screen.

\section{Design and Materials}

The main experiment was factorially designed, the two variables being \# vs $\$$ as the pre- and postmask characters, and change vs no change in the nontarget locations on SL trials. Four Ss each were assigned to Groups 1 and 2 , for which the display sequences on SL trials are shown in the first two lines of Table 1. Group 1 had \$ noise characters in the pre- and postmasks and at the nontarget locations on SL trials. Group 2 had \# pre- and postmasks but $\$ s$ in the nontarget locations on SL trials. The other two groups, listed as Groups 3 and 4 in Table 1, are taken from the study of Bjork and Estes (1973). Replicability of data under similar conditions had proven sufficiently high in this series of experiments that there seemed no need to rerun these groups, especially since the data from the W and NW conditions would provide a check on comparability.

For all display types, the target characters were the letters $\mathrm{R}$ and $L$. The display sequences, except for the mask characters on SL trials, were identical to those of Bjork and Estes (1973). The W displays were constructed so that replacing the presented with the nonpresented signal letter would change one half of these displays into NW displays (e.g., Trap-Tlap) and would keep the other half of them as W displays (e.g., Fork-Folk). Similarly, replacing the presented with the nonpresented signal letter would change half of the NW displays into W displays and would keep the other half as NW displays. The purpose of this arrangement is to insure that no strategy the $S$ inay adopt for guessing on the basis of context can alter his average performance level on the detection task.

The total set of 288 experimental displays was divided into blocks of 72 trials, any one block containing equal numbers of $\mathrm{W}, \mathrm{NW}$, and SL displays, with R and L appearing equally often in each serial position of each display type. Each $S$ received a different random ordering of the four blocks of trials. In addition, each $S$ received a practice block of 72 trials, the same for all Ss and constructed in the same manner as the experimental trial blocks, before beginning the main series.

In the subsidiary experiment, four Ss were run under the same conditions as those of Group 1 except that an upward pointing 
arrow appeared under the position that had been occupied by the target during the presentation of the postmask on each trial.

\section{RESULTS}

First, we need to check on the comparability of Groups 3 and 4, drawn from the Bjork and Estes (1973) study, with Groups 1 and 2. Since the treatments of Groups 1 and 4 and Groups 2 and 3 were identical on W and NW trials, the proportions of correct detections on these trials, given in the two right-hand columns of Table 1, provide the needed basis of comparison. It can be seen that the values obtained for Groups 3 and 4 under these conditions are closely recovered in Groups 1 and 2.

Turning then to the effects of the independent variables, it is immediately apparent that both type of mask character and change vs no change have substantial effects on performance under the SL condition. For each type of pre- and postmask, there is a higher percentage of correct detections for the no change condition and at each change condition there is a large advantage for the \# over the \$ mask. The SL condition is superior to the other display types under all combinations of the two independent variables except the change condition with $\$$ mask; and there are no W-NW differences under any conditions.

An analysis of variance of these detection data shows the main effects of display type and type of mask to be significant at the .01 level $(\mathrm{F}=22.9, \mathrm{df}=2 / 24$, and $\mathrm{F}=$ 42.9 , df $=1 / 12$, respectively), but the main effect of change vs no change is not significant. However, the interaction of change vs no change by display type is significant at the $1 \%$ level $(F=6.9, \mathrm{df}=2 / 24)$, and the interaction of Mask by Display Type yields $\mathrm{F}=3.38 \mathrm{df}$ $=2 / 24$, where 3.40 is required for significance at the $5 \%$ level. Utilizing the error term from the analysis of variance, we obtain an estimate of $2 \%$ as the standard error of the values given in Table 1 .

The group run in the subsidiary experiment, under the mask conditions of Group 1, but with the postexposure cue for position, shows an across-the-board increase in percentages of correct detections, the values being 73 , 65 , and 64 for the SL, W, and NW displays, respectively, but the overall difference between this group and Group. 1 is not significant in an analysis of variance. The standard error of the percentages for the postcue group is $3 \%$. The SL advantage persists under the postcue condition, though possibly somewhat reduced, and again there is no W-NW difference.

\section{DISCUSSION}

In agreement with nearly all ${ }^{1}$ previous experiments utilizing a detection procedure with target letters known in advance, this study has yielded consistently superior detection of single letters over letters embedded in words or nonwords, as predicted on the basis of models assuming that the extraction of information from a tachistoscopic display is limited by signal-noise confusability either at the perceptual level (Estes, 1972) or at the decision level (Gardner, 1973; Shiffrin \& Geisler, 1973). The basis for the prediction is that a heterogeneous set of noise letters includes a larger total number of visual features potentially confusable with those of the target letter than a homogeneous set of noise letters. The present results together with those of Bjork and Estes (1973) indicate that the inhibitory effect of noise characters included in the display involves component processes occurring both at display onset and during the steady state portion of the display exposure.

Taking together all of the studies so far reported comparing perception of single letters with letters in words under the detection procedure, we can identify three factors which appear to combine almost additively in determining the magnitude of the SL advantage. Other things equal, the advantage is increased (1) if there are blank spaces adjacent to the target letter in the SL condition, (2) if the pre- and postmask characters yield relatively weak pattern masking, and (3) if there is no change of characters from premask to display to postmask at the nontarget positions in the SL displays.

But within wide limits, no one of these factors by itself is critical. Thus, we find a SL advantage even when characters at nontarget locations change at display onset, provided that the pre- and postmasks are not too effective (Group 2 of the present study) and even with highly effective pre- and postmasks provided that there is no change in nontarget locations at the display onset (Group 1 of the present study). Clearly, there is no one answer to the question whether target letters known in advance are better detected when presented alone than when embedded in words. Rather, the difference depends on a number of identifiable conditions having to do with the effectiveness of premasking, postmasking and la teral masking.

The design of the Bjork and Estes (1973) study and the present study insure that Ss cannot improve their detection performance by adopting guessing strategies in which they choose letters that complete words on trials when they fail to perceive the target letters. The intent in these studies was to eliminate any contributions from guessing strategies in order to determine whether a word context facilitates the perception of embedded letters. The results to date provide no positive indication of any effect of word context at the perceptual level when the task is detection of predesignated target letters.

\section{REFERENCES}

Bjork, E. L., \& Estes, W. K. Letter identification in relation to linguistic context and masking conditions. Memory \& Cognition, 1973, 1, 217-223.

Estes, W. K. Interactions of signal and background variables in visual processing. Perception \& Psychophysics, 1972, 12, 278-286.

Gardner, G. T. Evidence for independent parallel channels in tachistoscopic perception. Cognitive Psychology, 1973, 4 , 130-155.

Massaro, D. W. Perception of letters, words, and nonwords. Journal of Experimental Psychology, 1973, 100, 349-353.

Reicher, G. M. Perceptual recognition as a function of the meaningfulness of the material. Journal of Experimental Psychology, 1969, 81, 275-280.

Shiffrin, R. M., \& Geisler, W. A. Visual recognition in a theory of information processing. In R. L. Solso (Ed.), Contemporary issues in cognitive psychology: The Loyola symposium. Washing ton, D.C: Winston, 1973. Pp. 53-101.

Thompson, M. C., \& Massaro, D. W. Visual information redundancy in reading. Journal of Experimental Psychology, 1973, 98, 49-54.

Wheeler, D. D. Processes in word recognition. Cognitive Psychology, 1970, 1, 59-85.

\section{NOTE}

1. The single exception known to us is one condition of the study of Reicher (1969) in which the Ss were informed of the target letters auditorily prior to each trial and required to pronounce the letters before display onset. This variation in procedure did not eliminate the word advantage obtained under other conditions in Reicher's study, but it had the surprising effect of reducing the accuracy of letter identification. This result, obtained with Ss who had previously been trained to respond without precues in the same situation, requires further investigation.

(Received for publication December 20,1973.) 